\title{
Inhibitory effect of gefitinib derivative LPY-9 on human glioma
}

\author{
YUCHEN SUN ${ }^{1-3}$, LIANGZHAO CHU ${ }^{1}$, HUIJUAN WANG ${ }^{4}$, HAN PENG $^{1}$ and JIAN LIU ${ }^{1,2}$ \\ ${ }^{1}$ Department of Neurosurgery, Affiliated Hospital of Guizhou Medical University; ${ }^{2}$ Department of Pathology \\ at Basic Medical College of Guizhou Medical University, Guiyang, Guizhou 550000; ${ }^{3}$ Department of Neurosurgery, \\ The Second Hospital of Hebei Medical University; ${ }^{4}$ Department of Neurology, The Second Hospital \\ of Hebei Medical University, Shijiazhuang, Hebei 050000, P.R. China
}

Received November 20, 2018; Accepted January 29, 2021

DOI: $10.3892 / \mathrm{mmr} .2021 .12262$

\begin{abstract}
The present study aimed to investigate the effects of a gefitinib derivative, LPY-9, on the proliferation, apoptosis and migration of human glioma cell line U251-MG by CCK8, Transwell or flow cytometry, and the effect of LPY-9 on the activity of caspase- 3 enzyme and related proteins in the vascular endothelial growth factor (VEGF) and epidermal growth factor receptor (EGFR) pathways by western blot and ELISA. It was found that LPY-9 exhibited higher a inhibitory effect on the proliferation of U251-MG cell lines compared with gefitinib and it also exhibited a certain dose-dependence. Following LPY-9 treatment, typical apoptotic morphology was observed under the microscope after Giemsa staining. LPY-9 induced apoptosis at low concentration, and the activity of caspase-3 enzyme increased with the increase in drug concentration, significantly inhibiting the secretion of VEGF in a dose-dependent manner. The effect was notably more evident compared with gefitinib at the same concentration. The expression level of caspase-3 and cleaved caspase-3 increased with the increase in LPY-9 concentration; however, expression levels of VEGF, EGFR, phosphorylated AKT and PI3K decreased with the increase of LPY-9 concentration and no change was observed in the expression level of AKT. LPY-9 inhibited the proliferation of the human glioma cell line U251-MG, promoted apoptosis and effectively inhibited the migration of U251-MG cells. The effect of LPY-9 was more noticeable compared with gefitinib. The results of the present study may provide a foundation for further study and clinical research of this as an anti-tumor drug in animal models.
\end{abstract}

\section{Introduction}

Glioma is the most common primary malignant tumor arising from the neuroectodermal central nervous system with poor

Correspondence to: Professor Jian Liu, Department of Neurosurgery, Affiliated Hospital of Guizhou Medical University, 28 Guiyi Street, Guiyang, Guizhou 550000, P.R. China

E-mail: lifesciencehx@163.com

Key words: LPY-9, gefitinib, apoptosis, proliferation, vascular endothelial growth factor, AKT, phosphorylated AKT, PI3K prognosis, accounting for 50-60\% of intracranial tumors (1). Glioma is usually treated by surgery, followed by chemotherapy combined with radiotherapy (2). However, the average survival time of the patients with low grade glioma is only 3-5 years and 1-2 years in the case of patients with high grade glioma (3). The conventional treatment of glioma involves the removal of most of the tumor by craniotomy, followed by several methods that are used to inhibit the proliferation of residual tumor cells or to kill the remaining tumor cells (4). However, even for patients with the same WHO level and pathological type of glioma, such as WHO I, II and III the prognosis is quite different (5). This is due to the difference in treatment strategy. The biological characteristics of tumors, especially the differences in heredity, gene, and protein, also play an important role (2). With the development of molecular biology, immunology, biochemistry, and other related disciplines, researchers have taken the treatment of glioma from the traditional approach, as outlined above, to the targeting of glioma cells, oncogene genes and related proteins (6).

Epidermal growth factor receptor (EGFR), a membrane receptor with tyrosine kinase activity, is widely expressed in various human cancers (7). The EGFR-mediated signal transduction pathway is complex and has various effects, which can induce cell proliferation, migration and differentiation, and is closely related to cell regeneration and the development of malignant tumors (8). EGFR is the first receptor in solid tumors to be used as a therapeutic target (9). Previous findings have shown that there is a high expression of EGFR in human glioma (10-12). Thus, it can be used as a target for human glioma and for combining with the ligands of chemotherapeutic drugs and be involved in targeted therapy (11).

Previous studies have shown that the application of targeted therapy is relatively safe and effective; however, there are issues that remain to be solved, including the therapeutic effect of targeted therapy and its predictability, how to combine the targeted therapy with the conventional therapy and improve the curative effect, the drug resistance of the tumor cells, and the single factor and the single target drug research and development strategy, which is inadequate to prevent and control multiple factors and multiple targets (12-14).

Gefitinib, an epidermal growth factor receptor antagonist, is currently widely used in the treatment of non-small cell lung cancer (15-17). Although glioma also expresses high levels of epidermal growth factor receptor, it has been shown that gefitinib is not effective in the treatment of glioma (18). 
The present study investigated the underlying molecular mechanism, modification and synthesis of gefitinib. A series of gefitinib derivatives were produced by the chemical modification of gefitinib, introducing hydrophilic groups and anti-tumor groups.

To develop more active small molecules targeting anticancer drugs, the present study used quinazoline as the research subject because it exhibits relatively suitable biological activities, including anticancer, bactericidal, insecticidal and antiviral properties (19-21). Quinoline compounds play an important role in tumor therapy and inhibit EGFR tyrosine kinase, vascular endothelial growth factor receptor, platelet derived growth factor receptor, FMS like tyrosine kinase 3 and other targets (22-25).

In previous studies, a few anticancer compounds were derived by introducing small molecular heterocycles on the four sites of quinazoline (including pyridine, pyrimidine and pyrazole) $(26,27)$. Non-quinazoline heterocycles, such as Tozasertib, also have relatively effective anticancer activities. Therefore, the present study used gefitinib as the precursor compound and introduced small molecular heterocyclic rings to its four sites, in order to achieve the 'superposition' of the activity and obtain more anticancer compounds.

\section{Materials and methods}

Chemicals, antibodies, and reagents. LPY-9 and gefitinib were provided by Guizhou University School of Pharmacy. U251-MG cells were obtained from Procell. Fetal bovine serum (FBS) was purchased from Gibco (Thermo Fisher Scientific, Inc.; 10091148). DMEM was purchased from Hyclone (GE Healthcare Life Sciences; SH30022.01). DMSO was purchased from Sigma-Aldrich (Merck KGaA). CCK-8 proliferation toxicity test kit was obtained from Dojindo Molecular Technologies, Inc. (CK04), Giemsa staining kit was obtained from Beijing Solarbio Science \& Technology Co., Ltd. (G4641), PI-Annexin V double dye flow reagent kit was obtained from Nanjing KeyGen Biotech. Co., Ltd. (40303ES20). Caspase-3 Enzyme Activity kit was purchased from Nanjing KeyGen Biotech. Co., Ltd. (41345ES50), Transwell assay kit was obtained from Corning Inc. (3428), BCA protein quantitative kit was obtained from GenStar Biosolutions (E162-05).

Cell culture. The U251-MG cells were obtained from Procell and cultured using DMEM supplemented with 10\% FBS, $1 \%$ sodium pyruvate $(100 \mathrm{mM}), 1 \%$ non-essential amino acids (10 $\mathrm{mM}$ ), and $1 \%$ penicillin/streptomycin solution (Invitrogen; Thermo Fisher Scientific, Inc.). Cells were maintained at $37^{\circ} \mathrm{C}$ under a $5 \% \mathrm{CO}_{2}$ atmosphere. The cells were passaged after every 2 days.

Cell Counting Kit-8. U251-MG cells ( $2 \times 10^{4}$ cells/well) were seeded in 96-well plates and incubated for $24 \mathrm{~h}$ at $37^{\circ} \mathrm{C}$ followed by treatment with different concentrations of gefitinib and LPY-9. Then, $10 \mu \mathrm{l}$ of CCK-8 solution (Dojindo Molecular Technologies, Inc.) was added to each well and incubated for $4 \mathrm{~h}$. The samples were then detected at $450 \mathrm{~nm}$ by a microplate reader (Bio-Rad Laboratories, Inc.), and analyzed using the formula: [(OD value of test-OD value of
blank)/(OD value of control-OD value of blank)], to quantify the cell viability.

Giemsa staining. According to the results of CCK-8 assay, U251-MG cells were treated with 15,30 or $60 \mu \mathrm{mol} / 1$ LPY-9, or the same concentrations of gefitinib. After 24 h, U251-MG cells were fixed with methanol and washed carefully twice, and were then incubated with $10 \%$ Giemsa stain at room temperature for $10 \mathrm{~min}$ and washed carefully twice. Finally, the cell morphology was observed, and images captured, under an inverted microscope in three different fields at random.

Caspase-3 activity. To investigate caspase- 3 activity, $4 \times 10^{6}$ cells were collected according to the manufacturer's protocol of an ELISA kit (Biovision, K4221-100). After washing with PBS twice, lysis buffer was added into cells, mixed, incubated for $30 \mathrm{~min}$ on ice, and oscillated four times (each time $10 \mathrm{sec}$ at 3,000 rpm). Then, the cells were centrifuged at 8,000 x g at $4^{\circ} \mathrm{C}$ for $30 \mathrm{~min}$, and protein was quantified by a BCA kit.

Wound healing assay. Prior to seeding cells, three straight lines were drawn parallel to the bottom of a 6-well using marker pen. Cells were seeded in 6-well plates and cultured in a DMEM containing $1 \% \mathrm{FBS}, 1 \%$ penicillin/streptomycin solution in order to protect cell proliferation, although the usage of FBS is a limitation of the present study. After the cells adhered to the wall and formed a monolayer, a $200 \mu 1$ pipette tip was used to make three parallel scratches, followed by washing with PBS to remove the delimiting cells. Then the cell migration was observed with a light microscope (magnification $\mathrm{x} 10$ ) in three different fields.

Effects of LPY-9 and gefitinib on VEGF secretion. The effects of LPY-9 and gefitinib on VEGF secretion were detected using an ELISA kit. U251-MG cells were treated with 15, 30 or $60 \mu \mathrm{mol} / 1$ LPY-9, or 15,30 or $60 \mu \mathrm{mol} / 1$ gefitinib. ELISA for VEGF (ab65345, Abcam) was performed following the manufacturer's protocol.

Transwell assay. U251-MG cells were digested at log phase and washed with PBS. The cells were suspended in 3\% FBS containing DMEM, and the cell density was adjusted to $5 \times 10^{5}$ cells $/ \mathrm{ml}$. Then, $200 \mu \mathrm{l}$ of cell suspension treated with $60 \mu \mathrm{mol} / 1$ of LPY-9 and gefitinib were added to the Transwell (cat. no. 3460, Corning Life Sciences, $8 \mu \mathrm{m}$ ) upper chamber. Then, $500 \mu 1$ DMEM medium containing 10\% FBS was added to the lower chamber and cultured for $12 \mathrm{~h}$ in $37^{\circ} \mathrm{C}$ under $5 \%$ $\mathrm{CO}_{2}$ incubator. The cells were fixed with $10 \%$ formaldehyde at room temperature for $10 \mathrm{~min}$ and stained using $10 \%$ Giemsa stain at room temperature for $10 \mathrm{~min}$ and then observed, and images captured, under a light microscope (magnification x10) in three different fields at random.

Cell apoptosis detection. The proportion of cells actively undergoing apoptosis was quantified by annexin and propidium iodide staining using the Annexin V-FITC Apoptosis Detection kit (Nanjing KeyGen Biotech, Co., Ltd.) and a Beckman flow cytometer (Beckman Coulter, Inc.) according to the manufacturer's instructions. Briefly, according to results of CCK-8 assay, the cells were treated with either $15 \mu \mathrm{mol} / 1$ 
gefitinib or $15 \mu \mathrm{mol} / 1$ LPY-9 and then harvested and washed with PBS twice. Then, $5 \mu \mathrm{l}$ Annexin V-FITC and $5 \mu \mathrm{l}$ PI were added and after mixing, the mixture was incubated at room temperature for $5 \mathrm{~min}$ in the dark and analyzed using FlowJo Software v10.5.3 (FlowJo LLC).

Western blotting. U251-MG cells were treated with 15,30 or $60 \mu \mathrm{mol} / 1 \mathrm{LPY}-9$ or gefitinib for $24 \mathrm{~h}$ and lysed with RIPA buffer (Yeasen Biotechnology (Shanghai) Co., Ltd.) on ice for $30 \mathrm{~min}$. Then $50-150 \mathrm{mg}$ of thermally denatured protein as detected by a BCA kit (GenStar Biosolutions) extract was loaded on a $10 \%$ polyacrylamide gel, electroblotted onto a nitrocellulose membrane and blocked at room temperature for $1 \mathrm{~h}$ with 5\% BSA. The membrane was then incubated with antibodies against caspase-3 (Cell Signaling Technology, Inc., 9662; 1:1,000), cleaved caspase-3 (Cell Signaling Technology, Inc., 9664; 1:1,000), VEGF (Bioworld Technology, Inc., BS91432; 1:1,000), EGFR (Sigma-Aldrich; Merck KGaA, SAB1306008; 1:1,000), AKT (Cell Signaling Technology, Inc., 4691; 1:1,000), p-AKT (Cell Signaling Technology, Inc., 9611; 1:600), PI3K (Cell Signaling Technology, Inc., 4249; 1:1,000) and GADPH antibody (Hangzhou Goodhere Biotechnology Co., Ltd., AB-P-R001; $1: 2,500)$ at $4^{\circ} \mathrm{C}$ overnight. The membranes were washed with PBS three times and incubated with HRP-labeled goat anti rabbit antibody from Boster Biological Technology Co., Wuhan, China (BA1054; 1:5,000) at room temperature for 2 h. ECL buffer (Yeasen Biotechnology (Shanghai) Co., Ltd.) was used to develop the blots. The X-ray film was dried and scanned with a scanner. Glyko Bandscan 5.0 software (Glyko Inc.) was used to analyze the gray value of the film after scanning the obtained image. The relative expression level of the protein was expressed by normalizing against internal reference protein.

Statistical analysis. Statistical analysis was performed using SPSS17.0 software. The differences were evaluated using one way or two-way ANOVA followed by Tukey's test. Error bars represent standard deviation (SD), and three independent experiments were performed for each assay All statistical analyses and comparisons were made against a control group. Histograms were drawn using GraphPad Prism 5.01 (GraphPad Software, Inc.) and every figure was combined using Photoshop CS6 (Adobe Systems, Inc.). $\mathrm{P}<0.05$ was considered to indicate a statistically significant difference.

\section{Results}

Construction of gefitinib derivative, GLPY-9. In the present study, gefitinib was used as a parent compound to introduce some novel heterocycles into its four sites in order to achieve the superposition of activity and obtain compounds with higher anti-cancer activity than gerfitinib. In addition, the functional group at 6 and 7 position of quinazoline was also exchanged (Fig. 1A).

Observation of cell morphology. The human glioma U251-MG cells grew rapidly and adhered. The shape of U251-MG cells included spindle, star and irregular shapes. The cells had strong luminance, strong refraction in the cell body, and the nuclei were round and oval (Fig. 1Ba and b). The cells that were treated with different concentrations of LPY-9 grew slowly, their cell bodies became smaller, cell synapse decreased and their transparency decreased. Their cell morphology was significantly different compared with normal glioma cells; the intercellular space was enlarged and the cell debris were visible. The number of parietal cells decreased significantly with the increase of drug concentration (Fig. 1Bc and e). Compared with the same concentration of gefitinib, LPY-9 exhibited more significant inhibitory effect on proliferation of glioma cells (Fig. 1B). Following Giemsa staining, the nuclei of normal U251-MG cells were stained uniformly purple, a large number of mitotic cells were observed and the cells were healthy (Fig. 1C). Following treatment with LPY-9, the cells showed nuclear condensation, nuclear fragmentation and nuclear dissolution (Fig. 1D). With an increase in drug concentration, the abovementioned effects became more prominent. Compared with cells treated with the same concentration of gefitinib, the changes in LPY-9-treated cells were significantly more evident compared with gefitinib-treated cells.

Effect of LYP-9 on the proliferation and apoptosis of U251-MG cells. After treatment of human glioma U251-MG cells with LPY-9 and gefitinib for $24 \mathrm{~h}$, a dose-dependent inhibitory effect $(\mathrm{P}<0.01)$ was identified, except at the dose of $0.9375 \mu \mathrm{mol} / 1(\mathrm{P}=0.208)$. The higher the LPY-9 and gefitinib concentration, the stronger the inhibition of U251-MG cells. The effect of LPY-9 was more prominent compared with that of gefitinib $(\mathrm{P}<0.01)$. The median inhibitory concentration $\left(\mathrm{IC}_{50}\right)$ of LPY-9 was $19.2265 \mu \mathrm{mol} / 1$, and $\mathrm{IC}_{50}$ of gefitinib was $38.2740 \mu \mathrm{mol} / 1$ (Fig. 2A).

The effects of LPY-9 and gefitinib on apoptosis of U251-MG cells were detected by the flow Annexin V/PI FITC double-labeling method. The induction of a significant level of apoptosis was found in the LPY-9 $(46.3 \pm 1.5875 \%)$ and gefitinib $(20.8 \pm 1.4731 \%)$ groups compared with the control group $(11.6 \pm 0.5568 \%$; $\mathrm{P}<0.01)$. Thus, the LPY-9-treated cells exhibited a higher apoptosis rate compared with gefitinib-treated cells $(\mathrm{P}<0.01$; Fig. 2B and $\mathrm{C})$.

Caspase-3 activity. In order to detect caspase-3 activity, ELISA were used to detect caspase-3 enzyme activity. As shown in Fig. 2D, both LPY-9 and gefitinib increased the activity of caspase- 3 in a dose-dependent manner and the difference was statistically significant $(\mathrm{P}<0.01)$. Specifically, at $15 \mu \mathrm{mol} / 1$, no significant difference in casepase-3 enzyme activity was observed between LPY-9 and gefitinib ( $P>0.05)$. At 30 and $60 \mu \mathrm{mol} / 1$, the enzyme activity of the two drugs was statistically different $(\mathrm{P}<0.01)$. At low concentrations, the effect of LPY-9 was similar to that of gefitinib. However, when the concentration increased, LPY-9 significantly increased the activity of casepase- 3 enzyme, and the effect was more evident compared with gefitinib $(\mathrm{P}<0.01)$ at the same concentration.

Effect of LPY-9 on cell migration and invasion. In order to explore the effect of LPY-9 and gefitinib on migration of U251-MG cells, scratch assay was used. After treatment with drugs for $24 \mathrm{~h}$, the cells in the control group exhibited normal migration (Fig. 3Aa and b); however, the migration of 
A
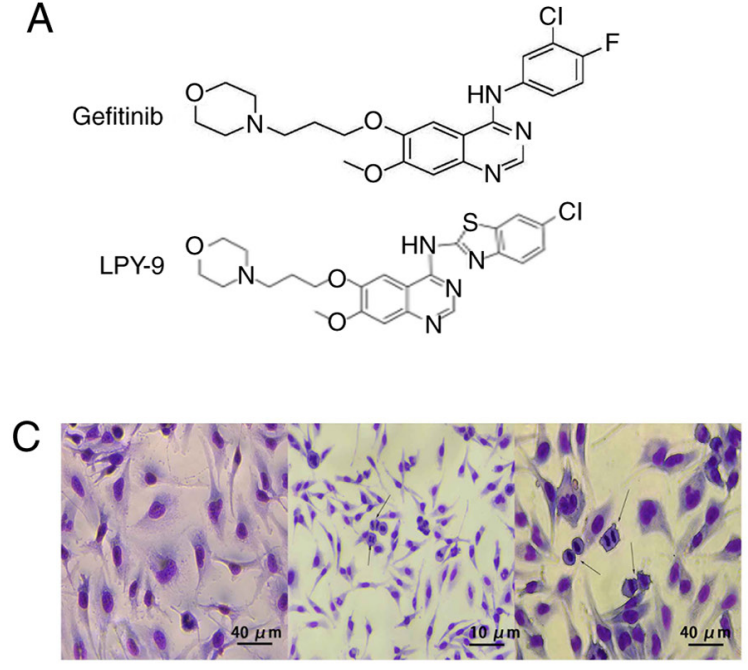

D

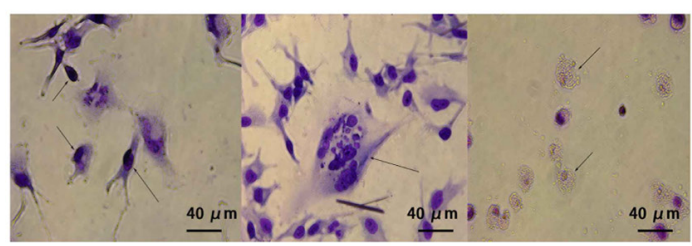

B
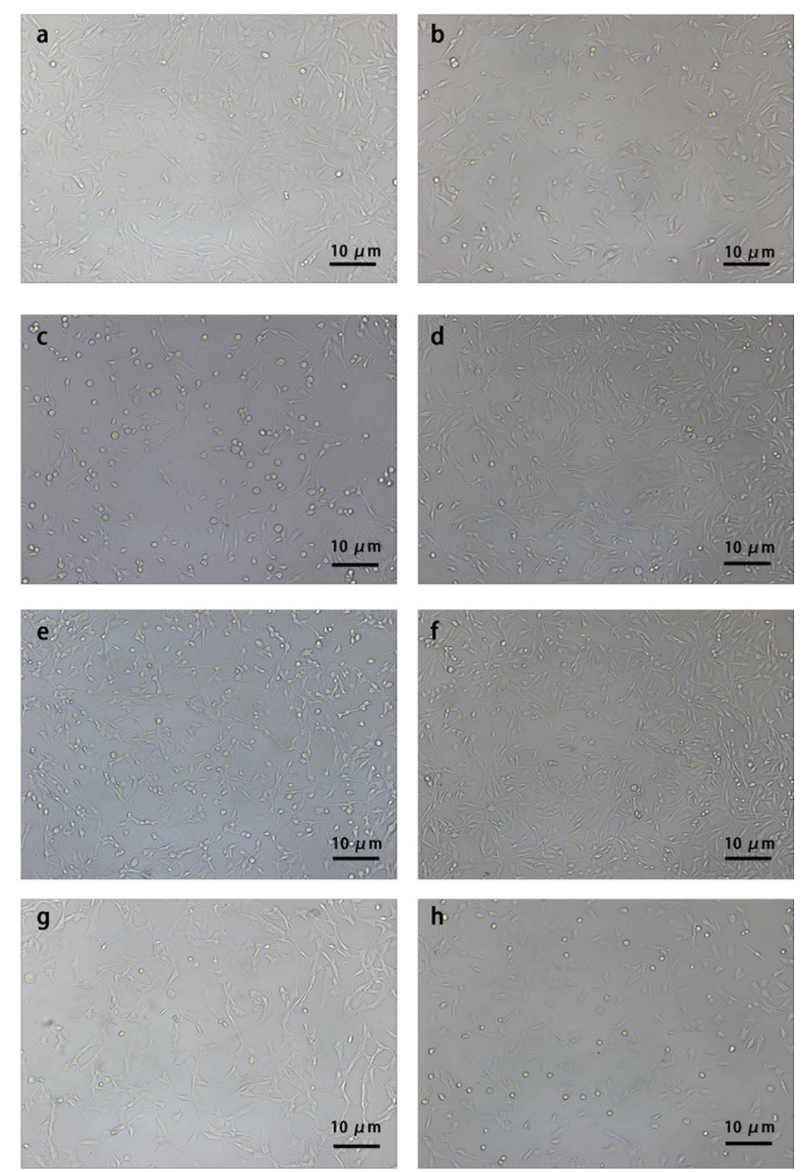

Figure 1. The effect of LPY-9 and Gefitinib on the morphology and structure of U251-MG cells. (A) The chemical structure of LPY-9. (B a and b) Untreated Human Glioma Cell U251 (magnification x100). (c, e and g) U251-MG cells were treated with 15, 30 and $60 \mu \mathrm{mol} / 1$ LPY-9 for $24 \mathrm{~h}$ (scale bar=10 $\mu \mathrm{m}$ ). (d, f and h) U251-MG cells were treated with 15, 30 and $60 \mu \mathrm{mol} / 1$ gefitinib for $24 \mathrm{~h}$ (scale bar=10 $\mu \mathrm{m}$ ). (C) Untreated U251-MG cells after Giemsa's staining; the cell nuclei were dyed uniform purple and numerous mitotic cell division cells were identified (indicated by arrows), the cells exhibited healthy morphology; scale bar $=40 \mu \mathrm{m}$. (D) Untreated U251-MG cells Following LPY-9 intervention and Giemsa's staining; scale bar=40 $\mu \mathrm{m}$.

cells of the LPY-9 group was not significant (Fig. 3Ac and d), and was even less than that of cells of the gefitinib group (Fig. 3Ae and f). The difference of migration distance was not statistically significant $(\mathrm{P}>0.05$; Fig. 3B). The Transwell assay was also used to detect cell migration. There were more cells in the blank control group (Fig. 4Aa and b), while LPY-9 (Fig. 4Ac and d) inhibited the migration of U251-MG cells, and the inhibitory effect of LPY-9 was significantly more compared with gefitinib ( $\mathrm{P}<0.01$; Fig. 4Ae and Af and $\mathrm{B})$.

Effects of LPY-9 and gefitinib on VEGF secretion. VEGF secretion was detected in the U251-MG cell media of different groups using ELISA. It was found that low and high concentration of LPY-9 significantly inhibited the secretion of VEGF protein, and the difference was statistically significant $(\mathrm{P}<0.01)$. The effect of LPY-9 did not change significantly with concentration $(\mathrm{P}>0.05)$. Compared with the gefitinib treatment group, the effect of LPY-9 was more evident (Fig. 5A) and the result was statistically significant $(\mathrm{P}<0.01)$.

Effects of LPY-9 and gefitinib on expression of caspase-3 and cleaved Caspase-3 protein. The expression of caspase- 3 and cleaved caspase- 3 protein in the normal cells was low. Following treatment with LPY-9 and gefitinib, the expression of caspase-3 and cleaved caspase-3 in U251-MG cells increased in a drug-dependent manner, and the difference was statistically significant $(\mathrm{P}<0.05)$. The expression level of caspase-3 protein in LPY-9-treated group was higher compared with the gefitinib-treated group $(\mathrm{P}<0.05)$. At a drug concentration of $15 \mu \mathrm{mol} / 1$, the expression of cleaved caspase- 3 protein in the gefitinib treatment group was higher compared with that of the LPY-9 treatment group. At drug concentrations of 30 and $60 \mu \mathrm{mol} / 1$, the expression of cleaved caspase-3 protein in the LPY-9 treatment group was higher compared with the gefitinib treatment group, and the difference was statistically significant $(\mathrm{P}<0.05)$ (Fig. 5B and C).

Effects of LPY-9 and gefitinib on VEGF and its subunit protein. The expression of VEGF and its subunit protein in the normal cells was high. Following treatment of LPY-9 and gefitinib, the expression of VEGF and its subunit decreased with the increase of drug concentration. At drug concentrations of 15 and $30 \mu \mathrm{mol} / 1$, the difference was not statistically significant (P>0.05). At $60 \mu \mathrm{mol} / 1$ concentration, the effect of LPY-9 and gefitinib increased significantly, and the difference was statistically significant $(\mathrm{P}<0.05)$. LPY-9 exhibited a greater inhibitory effect on VEGF, and the difference was statistically significant $(\mathrm{P}<0.05$; Fig. 5B and $\mathrm{D})$. 
A
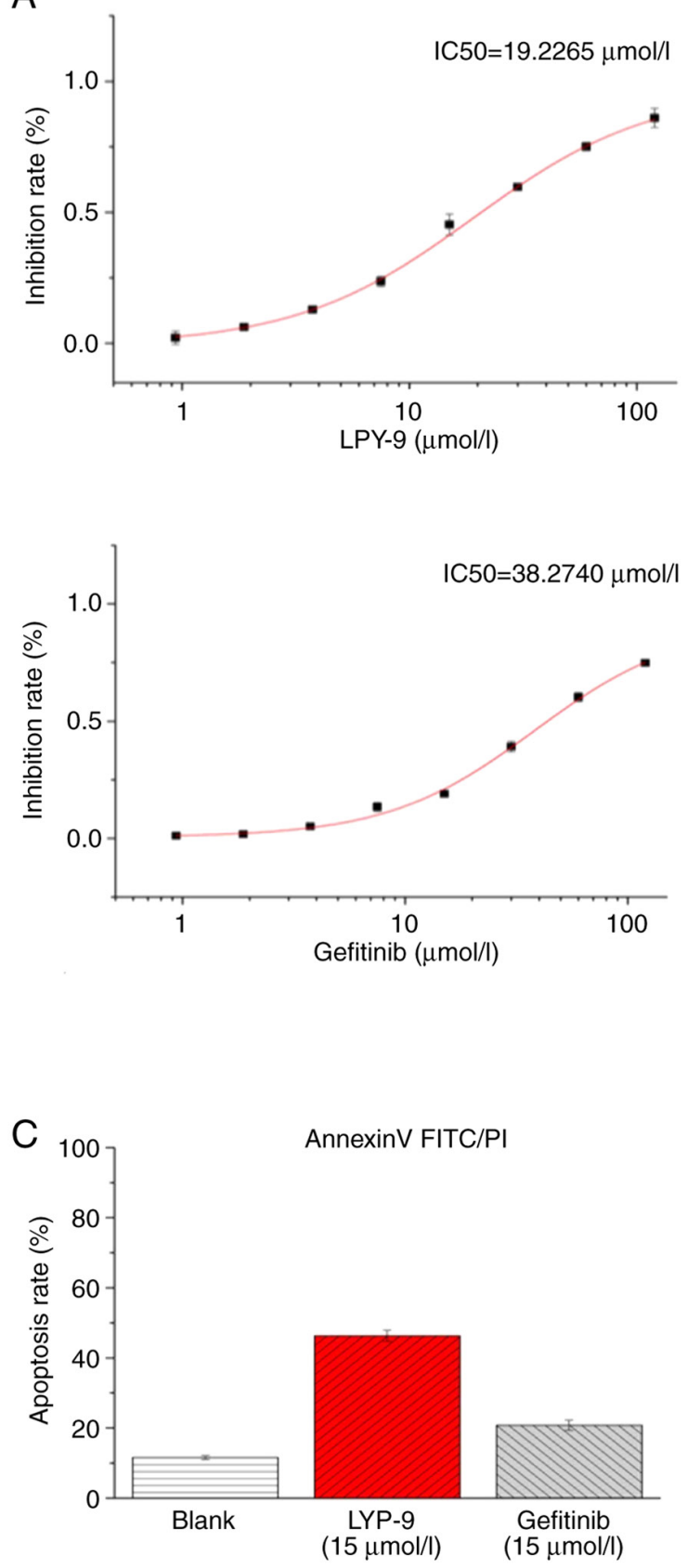

B
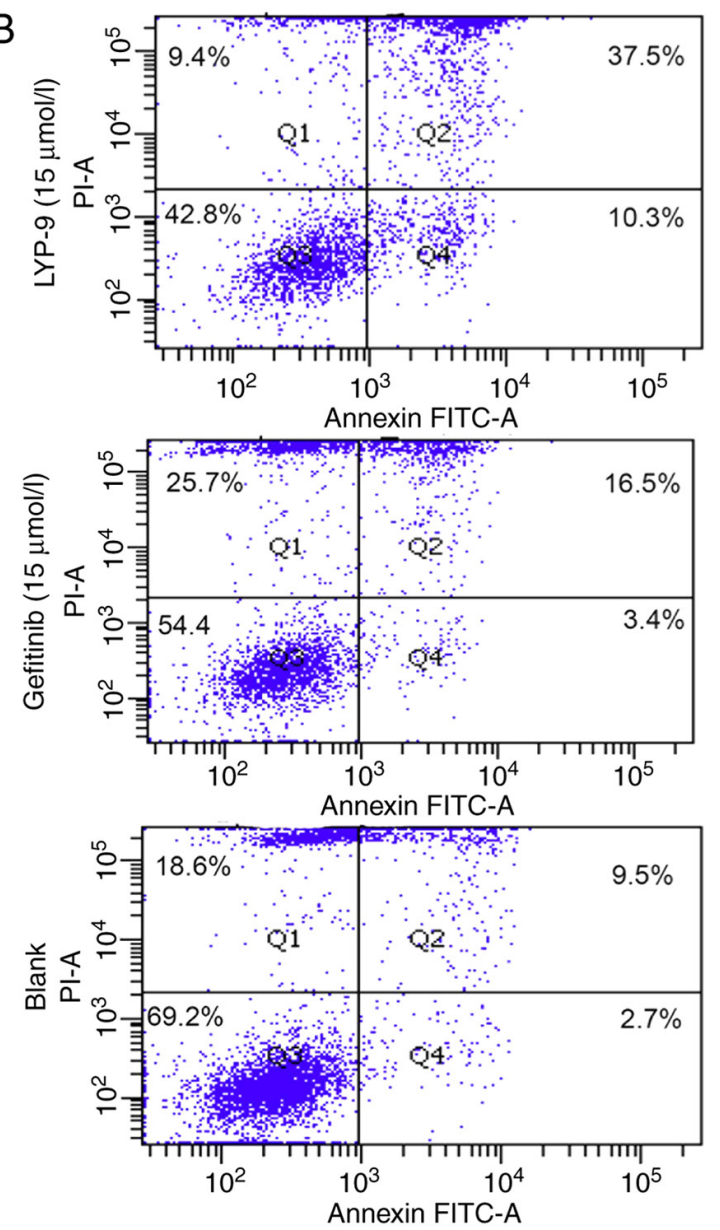

D

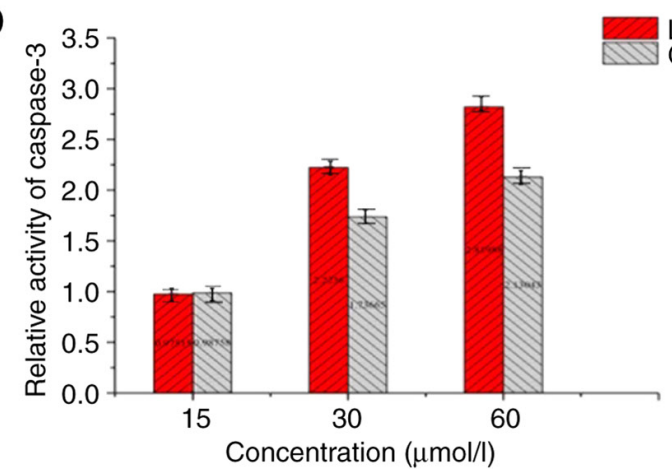

Figure 2. The effect of LPY-9 on cell apoptosis. (A) The inhibition rate standard curve of different concentrations of LPY-9 and gefitinib in U251-MG cells for $24 \mathrm{~h}$. (B)The apoptosis rate of U251-MG cells induced at the same concentration of LPY-9 and gefitinib as measured by flow cytometry. (C) The apoptosis statistical results of U251-MG cells induced at the same concentration of LPY-9 and gefitinib. (D) The influence of different concentrations of LPY-9 and gefitinib on caspase- 3 activity for $24 \mathrm{~h}$.

Effects of LPY-9 and gefitinib on EGFR protein. The expression of EGFR protein in the normal cells was high. Following treatment with LPY-9 and gefitinib, the expression of EGFR decreased, and the difference was statistically significant $(\mathrm{P}<0.01$ or $\mathrm{P}<0.05)$. By contrast, LPY-9 exhibited a greater inhibitory effect on EGFR expression. There was no significant difference in EGFR expression between LPY-9 and gefitinib groups when the concentrations of LPY-9 and gefitinib were 30 and $60 \mu \mathrm{mol} / 1$ ( $\mathrm{P}>0.05)$, but the effect was more prominent than that observed after treatment with $15 \mu \mathrm{mol} / 1$ drug concentration $(\mathrm{P}<0.05$; Fig. 5B and E).
Effects of LPY-9 and gefitinib on PI3K protein. The expression of PI3K protein in the normal cells was high. Following LPY-9 and gefitinib treatment, the expression of PI3K decreased in a dose-dependent manner $(\mathrm{P}<0.05)$. The effect at $15 \mu \mathrm{mol} / 1$ concentration was not significant $(\mathrm{P}>0.05$ and $\mathrm{P}>0.05)$. At relatively high concentrations, both gefitinib and LPY-9 showed a significant inhibitory effect on PI3K protein $(\mathrm{P}<0.05)$, while the effect of LPY-9 was greater compared with gefitinib $(\mathrm{P}<0.01$; Fig. 5B and $\mathrm{E})$.

Effects of LPY-9 and gefitinib on AKT and p-AKT protein. The expressions of AKT and p-AKT proteins in the normal cells 
A

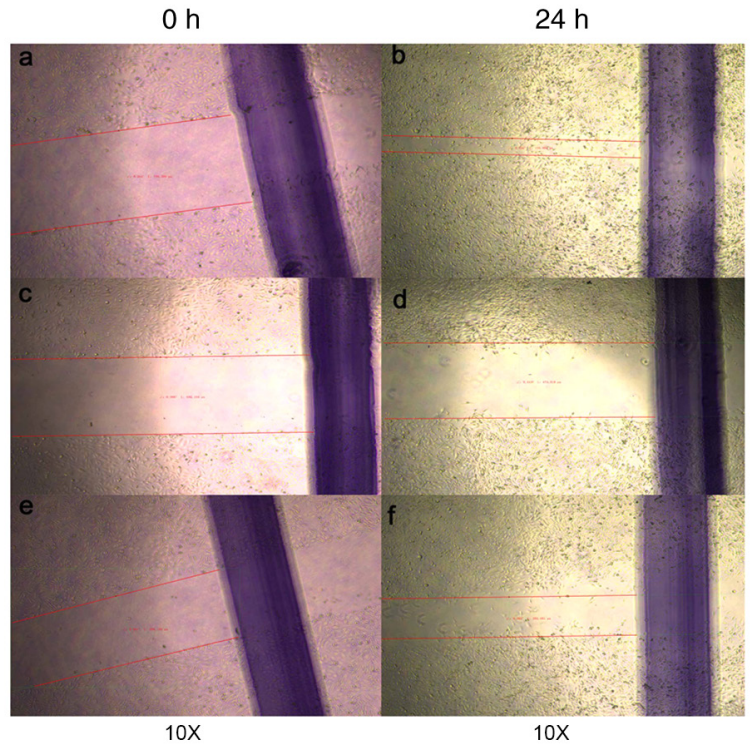

B

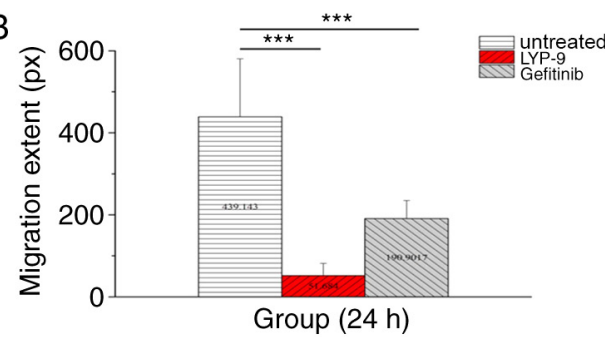

Figure 3. The migration distance after $24 \mathrm{~h}$ of different groups. (A) LPY-9 and Gefitinib were used to treat U251-MG cells at the same concentration for $24 \mathrm{~h}$, and cell migration distance was observed by microscope. a and b, untreated group; c and d, LPY group; e and f, Gefitinib group. (B) The migration distance after $24 \mathrm{~h}$ of different groups. ${ }^{* * *} \mathrm{P}<0.001$ as indicated.

were high. Following treatment with LPY-9 and gefitinib, no significant change was observed in the expression level of AKT $(\mathrm{P}>0.05)$. However, the expression of $\mathrm{p}$-AKT decreased significantly as the concentration of LPY-9 and gefitinib increased $(\mathrm{P}<0.01)$. By contrast, the inhibitory effect of LPY-9 was greater than gefitinib at the same concentration $(\mathrm{P}<0.01$; Fig. 5B and $\mathrm{E})$.

\section{Discussion}

Human glioma is one of the most common malignant tumors of the nervous system (1). Routine treatment includes surgical excision, followed by chemotherapy combined with radiotherapy (2). Patients with low malignancy usually have a survival period of 3-5 years; however, patients with higher malignancy have only 1-2 years of survival (3). As the incidence of glioma is on the increase annually, and the treatment not effective enough, it is necessary to develop new and improved treatment strategies.

Gefitinib is a type of epidermal growth factor receptor antagonist, which has been widely used in the treatment of non-small cell lung cancer, and glioma cells also express high levels of epidermal growth factor receptor (7). However, previous findings have shown that gefitinib is not effective in the treatment of glioma $(28,29)$.

The present study studied the molecular mechanism of glioma and the transformation and synthesis of

\section{A}
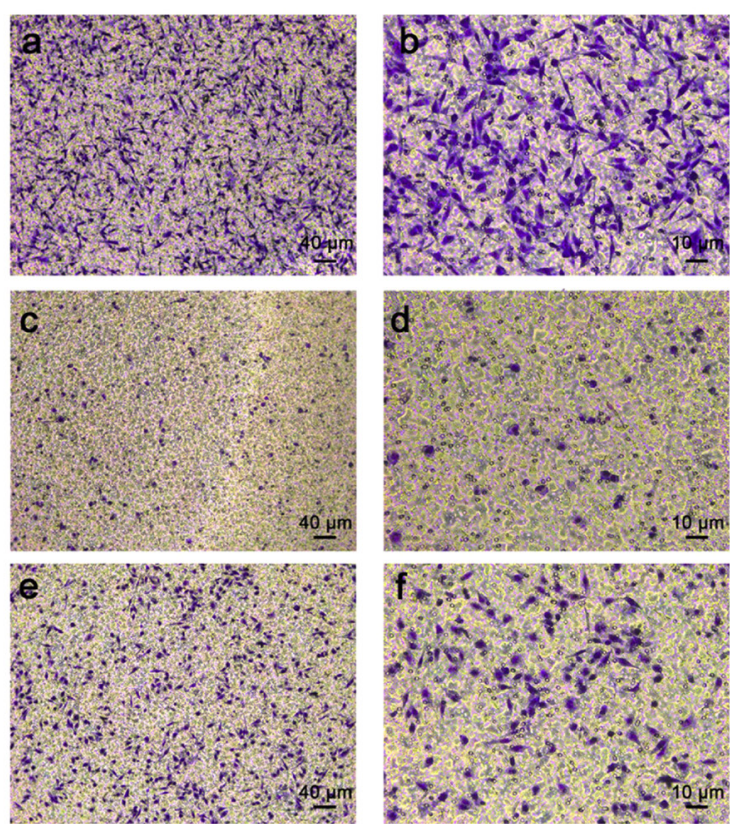

B

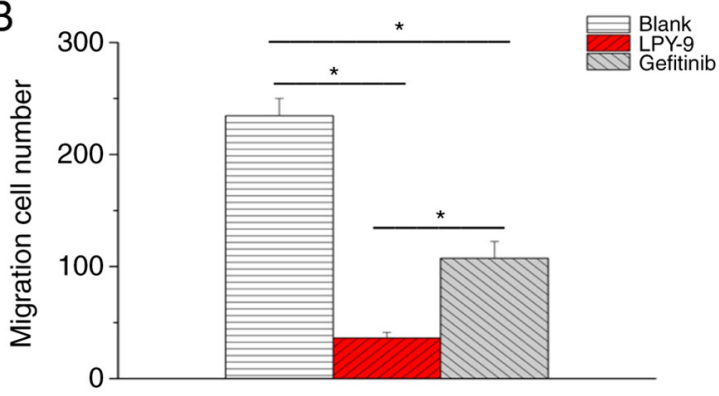

Figure 4. Detection of cell invasiveness by Transwell assay. (A) U251-MG cells were treated with the $60 \mu \mathrm{mol} / 1$ of LPY-9 and gefitinib for $12 \mathrm{~h}$. a and b, Untreated group. c and d, LPY-9 group; fewer migrating cells were found and most of the cells were morphologically different (spherical and irregular shapes) from the untreated U251 cells. e and f, Gefitinib group; some migration cells were found and the cells were morphologically similar to the untreated U251-MG cells. Scale bars $=40 \mu \mathrm{m}$ (a, c and e) and $10 \mu \mathrm{m}$ (b, d and f). (B) The number of migrating cells following treatment for $12 \mathrm{~h}$ in the different groups was statistically analyzed. Each data point represents the mean \pm SD of three independent experiments and were analyzed with a T-test. ${ }^{*} \mathrm{P}<0.05$.

chemotherapeutic drugs. These drugs were derived after chemical modification of gefitinib, such as introducing hydrophilic groups and antitumor active groups. The present study used the gefitinib derivative, LPY-9 and its effects on the glioma U251-MG cell line were investigated, to verify whether it was effective, and to explore the possible underlying mechanism of its action.

Cell migration is the movement of cells induced by stimulation of migration signals or gradients of concentration of certain substances and plays an important role in the metastasis of tumor cells. Using wound healing and Transwell assays, it was found that the cell migration in the normal U251-MG cell group was high and the cells could migrate in a short time period. The migration of U251-MG human glioma cells reduced after LPY-9 and gefitinib treatment. LPY-9 inhibited the migration of cells more significantly compared to gefitinib, which provided a basis for further research on the inhibition of cell invasiveness by LPY-9. 

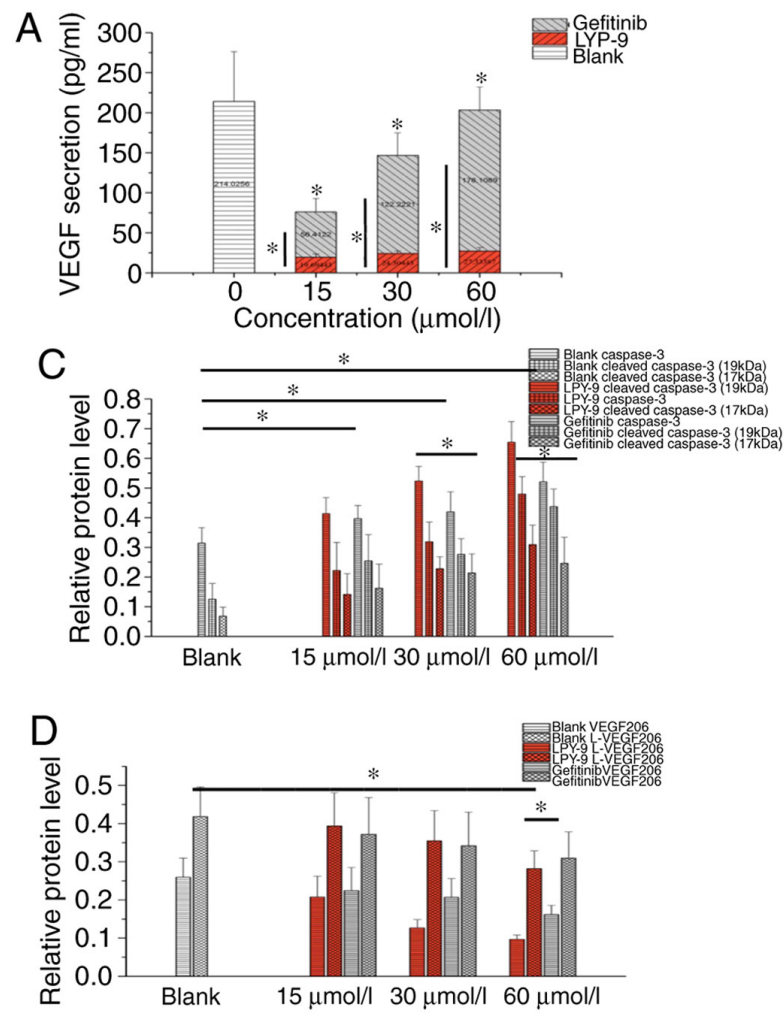

B

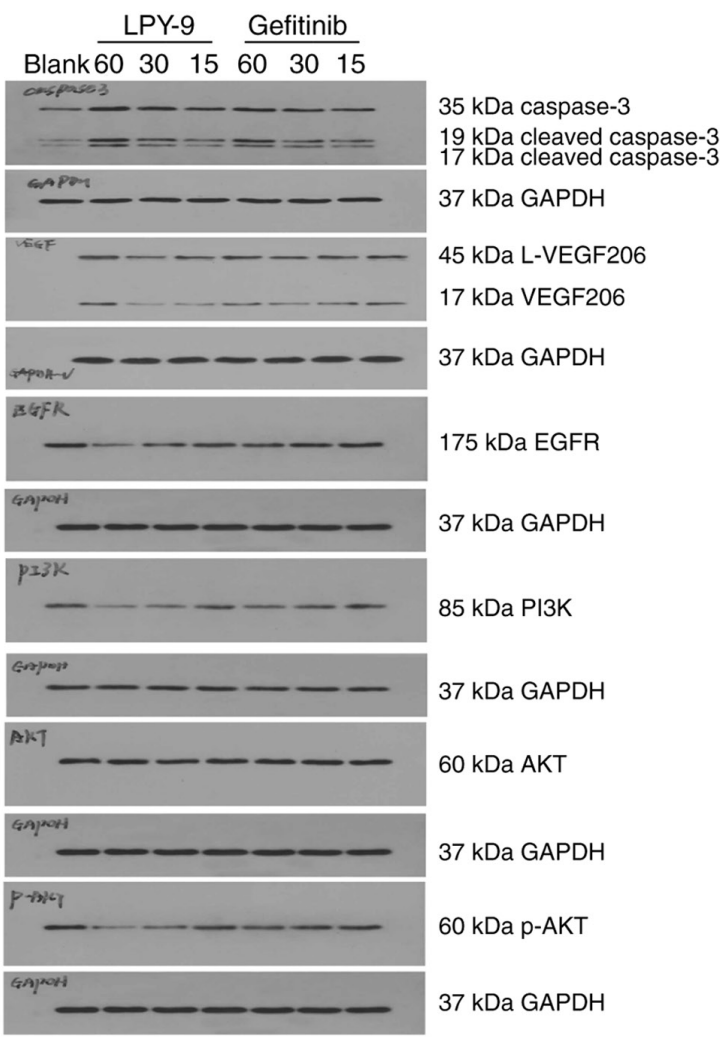

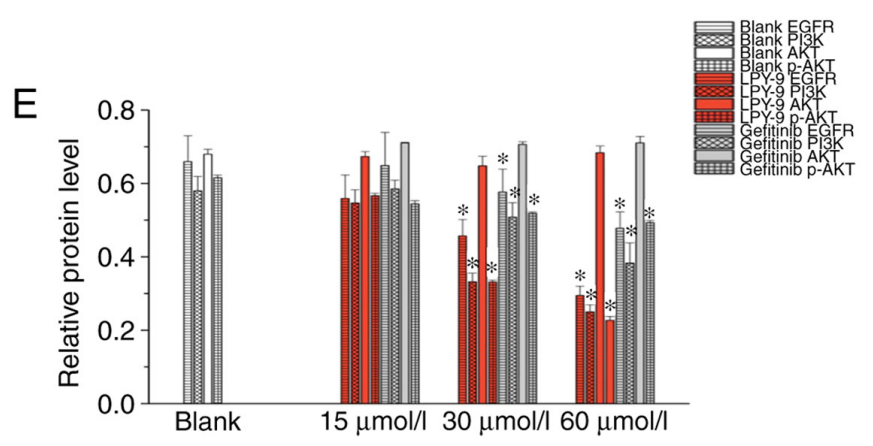

Figure 5. The detection of the signal pathway of the anti-tumor activity of LPY-9. (A) Following treatment of U251-MG cells with different concentrations of LPY-9 and gefitinib, the secretion of VEGF in the supernatant was detected by ELISA. (B) U251-MG cells were treated with different concentrations of LPY-9 and gefitinib for $24 \mathrm{~h}$, and the expression of anti-tumor related genes was detected by western blotting. (C-E) Statistical results of the expression of anti-tumor related proteins, including (C) Casepase-3 and cleaved casepase-3, (D) VEGF and VEGF subunit, and (E) EGFR and its related proteins. Each data point represents the mean $\pm \mathrm{SD}$ of three independent experiments and were analyzed with a T-test. ${ }^{*} \mathrm{P}<0.05$.

Apoptosis is a common feature in tumor cells and tissues. However, in tumor cells, due to the anti-apoptotic effect, the apoptosis rate of tumor cells decreases, and the abnormal proliferation of cells increases; the specific mechanism of tumor cells remains unclear $(30,31)$. The caspase family is the core link in the process of apoptosis. The degree of apoptosis depends on the activation and abnormal expression of caspase proteins $(32,33)$. The activation of caspase- 3 can lead to abnormal cell cycle and cell structure, and protein kinase inactivation, leading to cell apoptosis $(34,35)$. The present study found that the expression of caspase- 3 in glioma cells without any drug intervention was relatively low compared with drug intervention, which is consistent with the results of Chhanabhai et al (16). LPY-9 and gefitinib treatment significantly increased the expression of caspase-3 and the expression of cleaved caspase- 3 to induce apoptosis
$(\mathrm{P}<0.05)$, and the effect of LPY-9 was more prominent than gefitinib $(\mathrm{P}<0.05)$. The findings suggested that both drugs can promote cell apoptosis by increasing the expression level of caspase-3 and increasing its activation.

VEGF is a vasogenic factor commonly found in cells and tissues and promotes endothelial cell division, proliferation and angiogenesis by interacting specifically with VEGF receptor, which is closely related to the development, metastasis, and infiltration of tumors (36-38). In 1971, Folkman (36) first proposed that the tumor development depended on the neovascularization of its internal formation, and Nesbit (37) proposed that tumor tissue will not increase and may even deteriorate when the tumor volume is larger than $1 \mathrm{~mm}^{3}$ and no new blood vessels grow. As a result, researchers have turned their attention to inhibiting tumor growth by inhibiting tumor angiogenesis. Kil et al (38) 
showed that increased expression of VEGF promoted glioma U251-MG cell proliferation.

The present study analyzed the effects of LPY-9 and gefitinib on VEGF by ELISA and western blotting. It was found that the expression of both intracellular and extracellular VEGF was high. Following LPY-9 and gefitinib treatment, the levels of VEGF in the intracellular and secreted medium decreased significantly, in a dose-dependent manner. The effect of LPY-9 was greater than that of gefitinib.

EGFR is a transmembrane protein receptor, exhibiting the activity of tyrosine kinase. It is closely associated with the proliferation, invasion and anti-apoptotic ability of tumor cells. It has been found that the activity of EGFR in malignant tumors is significantly higher than that in normal cells $(39,40)$. The high expression of EGFR protein in glioma is considered a sign of abnormal differentiation, and with the increase of tumor malignancy the expression of the protein is significantly increased (41).

At present, a number of EGFR downstream signal transduction pathways are known, among which the main signal transduction pathways are the Ras/Raf/mitogen-activated protein kinase kinase/mitogen-activated protein kinase kinase 1 pathway, the $\mathrm{PI} 3 \mathrm{~K} / 3$-phosphoinositide dependent protein kinase $1 / \mathrm{AKT} / \mathrm{mTOR}$ pathway and the Janus kinase/STAT pathway (42). PI3K plays an anti-apoptotic role in many kinds of tumors (43). It is also one of the causes of induction of drug resistance in malignant tumor cells (44). AKT, also named PKB, is a serine/threonine protein kinase, which plays an important role in cell survival and apoptosis (45). Abnormal activation of PI3K/AKT pathway can increase the level of phosphorylated AKT in cells, leading to tumor resistance, reduced tumor necrosis and the promotion of the progression of malignant tumors $(46,47)$. The present study found that LPY-9 decreased the expression of EGFR, reduced the expression of PI3K and significantly inhibited the phosphorylation of AKT, thus promoting the apoptosis of tumor cells. Compared with gefitinib, LPY-9 exhibited a greater inhibitory effect on AKT phosphorylation.

Although the present study found that LPY-9 is more useful than gefitinib in treatment of U251-MG cells, whether LPY-9 was effective in other types of cancer cells will be investigated in the future. An effective anti-cancer drug does not only kill cancer cells, but also minimizes damage to normal cells. Future studies will further explore the effectiveness for other cancer cells and toxicity for normal cells.

In conclusion, LPY-9 and gefitinib effectively inhibited the proliferation and growth of human glioma U251-MG cells. By comparing two drugs, it was found that the effectiveness of LPY-9 was superior to gefitinib and that LPY-9 could exhibit significant effects at relatively low concentrations. By comparing the effects of LPY-9 and gefitinib on the migration of U251-MG cells in human glioma, it was found that both the drugs significantly inhibited the migration of tumor cells, and the effect of LPY-9 was more pronounced compared with gefitinib. In addition, LPY-9 also increased the levels of caspase- 3 and cleaved caspase- 3 in tumor cells, and increased the activity of caspase- 3 enzyme to promote the apoptosis of tumor cells; again, the effect was more pronounced compared with gefitinib. As a multi-target drug, LPY-9 exerted significant effects on caspase-3, cleaved-caspase-3, VEGF, EGFR,
p-AKT, PI3K and other proteins. Several target sites synergistically promoted apoptosis of tumor cells, and the effect of LPY-9 was more pronounced compared with gefitinib.

The experimental results of the present study demonstrated that the gefitinib derivative LPY-9 can be used as a multi-target targeted drug for the treatment of glioma, and it shows a more pronounced effect than Gefitinib. The authors are currently applying for the patent for LPY-9. After the patent document is approved, the authors will further disclose the preparation process of LPY-9, as well as the further data of water property, and toxicity, in order to conduct further research.

\section{Acknowledgements}

The authors thank Professor Guiping Ouyang of pharmacy school of Guizhou University for designing, producing and providing LPY-9 compound.

\section{Funding}

This work was funded by The Foundation of National Natural Science Foundation of China (grant no. 81560409) and Science Foundation of Guizhou Province of China [grant no. (2014) $6008]$.

\section{Availability of data and materials}

The datasets used and/or analyzed during the current study are available from the corresponding author on reasonable request.

\section{Authors' contributions}

JL conceived and designed the study. YS performed most of the experiments. JL wrote the manuscript and approved its publication, LC, HW and HP performed some of the experiments. All authors read and approved the final manuscript.

\section{Ethics approval and consent to participate}

Not applicable.

\section{Patient consent for publication}

Not applicable.

\section{Competing interests}

The authors have the patent rights for LPY-9.

\section{References}

1. Giesexs A and Westphal M: Glioma invasion in the central nervous system. Neurosurgery 39: 235-250, 1996.

2. Bush NA, Chang SM and Berger MS: Current and future strategies for treatment of glioma. Neurosurg Rev 40: 1-14, 2017.

3. Omuro A and Deangelis LM: Glioblastoma and other malignant gliomas: A clinical review. JAMA 310: 1842-1850, 2013.

4. Hopkins K, Chandler C, Eatough J, Moss T and Kemshead JT: Direct injection of 90Y MoAbs into glioma tumor resection cavities leads to limited diffusion of the radioimmunoconjugates into nomal brain parenchyma: A model to estimate absorbed radiation dose. Int J Radiat Oncol Biol Phys 40: 835-844, 1998 . 
5. Rudà R, Reifenberger G, Frappaz D, Pfister SM, Laprie A, Santarius T, Roth P, Tonn JC, Soffietti R, Weller M and Moyal EC: EANO guidelines for the diagnosis and treatment of ependymal tumors. Neuro Oncol 27: 445-456, 2017

6. Freije WA, Castro-Vargas FE, Fang Z, Horvath S, Cloughesy T, Liau LM, Mischel PS and Nelson SF: Gene expresion profiling of glioma strongly predicts survival. Cancer Res 64: 6503-6510, 2004.

7. Nicholson RI, Gee JM and Harper ME: EGFR and cancer prognosis. Eur J Cancer 37 (Suppl 4): S9-S15, 2001

8. Normanno N, De Luca A, Bianco C, Strizzi L, Mancino M, Maiello MR, Carotenuto A, De Feo G, Caponigro F and Salomon DS: Epidermal growth factor receptor (EGFR) signaling in cancer. Gene 366: 2-16, 2006.

9. Gadji M, Crous AM, Fortin D, Krcek J, Torchia M, Mai S, Drouin R and Klonisch T: EGF receptor inhibitors in the treatment of glioblastma multiform: Old clinicalallies and newly emerging therapeutic concepts. EurJ Pharmacol 25: 23-30, 2009.

10. Muracciole X, Romain S, Dufour H, Palmari J, Chinot O, Ouafik L, Grisoli F, Branger DF and Martin PM: PAI-1 and EGFR expression in adult glioma tumors: Toward a molecular prognostic classification. Int J Radiat Oncol Biol Phys 52: 592-598, 2002

11. Sun Y, Zhang W, Chen D, Lv Y, Zheng J, Lilljebjörn H, Ran L, Bao Z, Soneson C, Sjögren HO, et al: A glioma classification scheme based on coexpression modules of EGFR and PDGFRA. Proc Natl Acad Sci USA 111: 3538-3543, 2014.

12. Lin T, Wang M, Liang HS and Liu EZ: The expression of p53, mgmt and egfr in brain glioma and clinical significance. J Biol Regul Homeost Agents 29: 143-149, 2015.

13. Ladanyi $\mathrm{M}$ and Pao W: Lung adenocarcinoma: Guiding EGFR-targeted therapy and beyond. Mod Pathol 21 (Suppl 2): S16-S22, 2008

14. Lo HW: EGFR-Targeted therapy in malignant glioma: Novel aspects and mechanisms of drug resistance. Curr Mol Pharmacol 3: 37-52, 2010

15. Giaccone G: The role of gefitinib in lung cancer treatment. Clin Cancer Res 10: 4233s-4237s, 2004.

16. Hotta K, Ueoka H, Kiura K, Tabata M, Ogino A, Umemura S, Harita S, Gemba K, Yonei T, Bessho A, et al: Safety and efficacy of gefitinib treatment in elderly patients with non-small-cell lung cancer: Okayama lung cancer study group experience. Acta Oncol 44: 717-722, 2005.

17. Ostoros G, Harisi R, Kovacs G, Horti J, Geczi L, Szondy K, Orosz M, Ferenczi E, Ruby E, and Dome B: Inhibition of EGFR tyrosine-kinase in NSCLC treatment: The hungarian experience with gefitinib in the context of an expanded access programme. Anticancer Res 25: 4759-4762, 2005.

18. Antipenko L, Karpenko A, Kovalenko S, Katsev A Komarovska-Porokhnyavets E, Novikov V and Chekotilo A: Synthesis of New 2-Thio- $(1,2,4)$ triazolo(1,5-c)quinazoline derivatives and its antimicrobial activity. Chem Pharm Bul (Tokyo) 57: 580-585, 2009

19. Latli B, Wood E and Casida EJ: Insecticidal quinazoline derivatives with (trifluor-omethyl) diazirinyl and azido substituents as NADH: Ubiquinone oxidoreductase inhibitors and candidate photoaffinity probes. Chem Res Toxicol 9: 445-450, 1996.

20. Schleiss M, Eickhoff J, Auerochs S, Leis M, Abele S, Rechter S, Choi Y, Anderson J, Scott G and Rawlinson W: Protein kinase inhibitors of the quinazoline class exert anti-cytomegaloviral activity in vitro and in vivo. Antiviral Res 79: 49-61, 2008.

21. Barker AJ: Quinazoline derivatives useful for treatment of neoplastic disease. US Patent 5457105A. Filed August 2, 1994; issued October 10, 1995.

22. Lokker NA, Sullivan CM, Hollenbach SJ, Israel MA and Giese NA Platelet-Derived growth factor (PDGF) autocrine signaling regulates survival and mitogenic pathways in glioblastoma cells: Evidence that the novel PDGF-C and PDGF-D ligands may play a role in the development of brain tumors. Cancer Res 62: 3729-3735, 2002.

23. Cheng Y and Paz K: Tandutinib, an oral, small-molecule inhibitor of FLT3 for the treatment of AML and other cancer indications. IDrugs 11: 46-56, 2008.

24. Fan TJ, Han LH, Cong RS and Liang J: Caspase family proteases and apoptosis. Acta Biochim Biophys Sin (Shanghai) 37: 719-727, 2005.

25. Li GH, Zhang H, Liu Y, Kong L, Guo Q and Jin F: Effect of temozolomide on livin and caspase-3 in U251 glioma stem cells. Exp Ther Med 9: 744-750, 2015.
26. Zhang L, Hou L, Sun W, Yu Z, Wang J, Gao H and Yang G: Synthesis of p-O-Alkyl salicylanilide derivatives as novel EGFR inhibitors. Drug Dev Res 77: 37-42, 2016.

27. Yin KH, Hsieh YH, Sulake RS, Wang SP, Chao JI and Chen C: Optimization of gefitinib analogues with potent anticancer activity. Bioorg Med Chem Lett 24: 5247-5250, 2014.

28. Zhou J, Kwang KJ, Wu Z, Yang D, Li J, Chang M, Song Y, Zeng H, Lee LJ, Hu J and Bai C: PLAUR confers resistance to gefitinib through EGFR/P-AKT/Survivin signaling pathway. Cell Physiol Biochem 47: 1909-1924, 2018.

29. Blazar IN: Differential effects of epidermal growth factor receptor inhibitors on glioblastoma multiforme (unpublished $\mathrm{PhD}$ thesis). Boston University Theses \& Dissertations, 2015.

30. Li Y, Raffo AT, Drew L, Mao Y, Tran A, Petrylak DP and Fine RL: Fas-Mediated apoptosis is dependent on wild-type p53 status in human cancer cells expressing a temperature sensitive p53 mutant alanine-143. Cancer Res 63: 1527-1533, 2003.

31. Chhanabhai M, Krajewski S, Krajewska M, Wang HG, Reed JC and Gascoyne RD: Immunohistochemical analysis of interleukin-1beta-convertin enzyme/Ced-3 family protease, CPP32/Yama/Caspase-3, in Hodgkin's disease. Blood 15: 2451-2455, 1997

32. Riedl SJ and Shi Y: Molecular mechanisms of caspase regulation during apoptosis. Nat Rev Mol Cell 5: 897-907, 2004.

33. Creagh EM, Conroy H and Martin SJ: Caspase-Activation pathways in apoptosis and immunity. Immunol Rev 193: 10-21, 2003.

34. Leung SY, Chan AS, Wong MP, Yuen ST, Cheung N and Chung LP: Expression of vascular endothelial growth factor and its receptors in pilocytic astrocytoma. Am J Surg Pathol 21: 941-950, 2010.

35. Lassoued W, Murphy D, Tsai J, Oueslati R, Thurston G and Lee WM: Effect of VEGF and VEGF trap on vascular endothelial cell signaling in tumor. Cancer Biol Ther 10: 1326-1333, 2010.

36. Folkman J: Tumor angiogenesis: Therapeutic implications. N Engl J Med 285: 1182-1186, 1971.

37. Nesbit M: Abrogation of tumor vasculature using gene therapy. Cancer Metastasis Rev 19: 45-49, 2000.

38. Kil WJ, Tofilon PJ and Camphausen K: Post-Radiation in crease in VEGF enhances glioma cell motility in vitro. Radiat Oncol 7: 25, 2012.

39. Herbst RS and Shin DM: Monoclonal antibody to target epidermal growth factor receptor positive tumors: A new paradigm for cancer therapy. Cancer 94: 1593-1611, 2002.

40. Pore N, Jiang Z, Gupta A, Cerniglia G, Kao GD and Maity A EGFR tyrosine kinase inhibitors decrease VGFR expression by both hypoxia-inducible factor(HIF)-1-Dependent mechanism. Cancer Res 66: 3197-3204, 2006.

41. Bronte G, Terrasi M, Rizzo S, Sivestris N, Ficorella C, Cajozzo M, Di Gaudio F, Gulotta G, Siragusa S, Gebbia N and Russo A: EGFR genomic alterations in cancer: Prognostic and predictive value. Front Biosci (Elite ED) 1: 879-887, 2011.

42. Tao JJ, Castel P, Radosevic-Robin N, Elkabets M, Auricchio N, Aceto N, Weitsman G, Barber P, Vojnovic B, Ellis H, et al: Antagonism of EGFR and HER3 enhances the response to inhibitors of the PI3K-Akt pathway in triple-negative breast cancer. Sci Signal 7: ra29-ra29, 2014.

43. Lien EC, Dibble CC and Toker A: PI3K signaling in cancer: Beyond AKT. Curr Opin Cell Biol 45: 62-71, 2017.

44. McCubrey JA, Steelman LS, Abrams SL, Lee JT, Chang F, Bertrand FE, Navolanic PM, Terrian DM, Franklin RA, D'Assoro AB, et al: Roles of the RAF/MEK/ERK and $\mathrm{PI} 3 \mathrm{~K} / \mathrm{PTEN} / \mathrm{AKT}$ pathways in malignant transformation and drug resistance. Adv Enzyme Regul 46: 249-279, 2006.

45. Freudlsperger C, Burnett JR, Friedman JA, Kannabiran VR, Chen $Z$ and Van Waes C: EGFR-PI3K-AKT-mTOR signaling in head and neck squamous cell carcinomas-attractive targets for molecular-oriented therapy. Expert Opin Ther Targets 15: 63-74, 2011.

46. Luwor RB, Taylor LE, Wang B and Zhu HJ: Tumor-associated EGFR over-expression specifically activates Stat3 and Smad7 resulting in desensitization of TGF- $\beta$ signaling. Nat Prec, 2008.

47. Kim SH, Juhnn YS and Song YS: Akt involvement in paclitaxel chemoresistance of human ovarian cancer cells. Ann N Y Acad Sci 10: 82-89, 2007.

This work is licensed under a Creative Commons Attribution-NonCommercial-NoDerivatives 4.0 International (CC BY-NC-ND 4.0) License. 